\title{
أسلوب المناظرة بالمدخل الفعال في تعليم مهارة الكلام
}

\section{Fahrur Rozi S}

Program Studi Pendidikan Bahasa Arab Stai As-Sunnah Deli Serdang Jl. Medan-Tg. Morawa, km. 13, Gg. Darmo, Bangun Sari, Tg. Morawa, Deli Serdang, SUMUT Fahrur85ulfa@gmail.com

الملخص : الطريقة والأساليب التعليمية تلعب دورا هام في عملية التعليم، إذ أها تساعد وتسهل ارسال المادة إلى الطلبة والفهم بها. إن أخطأ اختيار الطريقة أو الأساليب التعليمية وتطبيقها قد يسبب إلى فساد التعليم، أي عدم اشتراك الطلبة في التعليم بجد وحماسة. وبالأكس، إن أصح اختيار الطريقة أو الأساليب التعليمية وتطبيقها قد يسبب إلى بحاح التعليم، أي اشترك الطلبة في التعليم بجد وحماسة. وعدم اختيار الطريقة أو إو الأساليب التعليمية المناسبة داخل الصف يسبب المشكالات التعليمية. ومن أحد الأساليب التعليم المثالي في تعليم مهارة الكالام هو أسلوب المناظرة.

الكلمات المفتاحية : أسلوب المناظرة، المدخال الفعال، مهارة الكلام

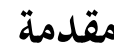

أشربت قلوب المسلمين حب اللغة العربية على اختلاف لغاهم، وتباين مشاركهم

في مشارق الأرض ومغاربها، بوصفها لغة القرآن الكريم والسنة النبوية الشريفة ـ واهتم كثير من العرب و المسلمين بتعلم اللغة العربية وتعليمها. يقول نايف بضعة وعشرون عاما قضيتها في رحاب اللغة العربية، مدرسا ومشرفا تربويا ومحاضرا في مختلف

$$
\text { والعلوم والثقافة، دون السنة) ص أحمد طعيم، تعليم العربية لغير الناطقين بها: مناهجه وأساليبه (الرباط: منشورات النظمة الإسلامية للتربية }
$$


مراحل التعليم، جعلت الألفة تزداد والأواصر تقوى فيما بيننا. فأصبحت تلميذا في محرابها، متدثرا بدفئها، ومستمتعا بخيراتها 2 تعليم اللغة، لاسيما العربية لابد أن يشمل على المهارات اللغوية الأربع، مهارة الاستماع، ومهارة الكلام، ومهارة القراءة، ومهارة الكتابة. وتعليم مهارة الكلام في الواقع لم يزل يواجه المشكلات. ومن أبرز المشكلات هي مشكلة عملية التعليم خاصة في اختيار طريقة التعليم المستخدمة، كانت الطريقة المستخدمة في التعليم أكثرها طريقة تقليدية. كانت الطريقة التقليدية تركز عملية التعليم تحت سيطرة المعلم، حيث أها لا توجد فرصة واسعة لدى الطلبة لممارسة مهارة الكلام ولاشتراك في عملية التعليم بجد

$$
\text { ونشاط وحرية. }
$$

اختيار الطريقة التقليدية في تعليم مهارة الكلام قد تأثر نفسية الطلاب في اشتراك التعليم. كان الطلاب لايشتركون عملية التعليم والتعلم بجد، ونشاط، وحماسة، بل منهم خائفين لممارسة الكالام العربي. والنتيجة ذلك، عدم قدرة الطلبة على التكلام العربي الكافية. فلذلك، ينبغى على المعلم اختيار الطريقة أو الأسلوب التعليمية الفعالة ليكون التعليم مثاليا. مثل استخدام الأسلوب المناظرة في تعليم مهارة الكلام. 


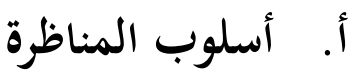

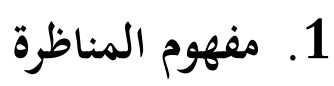

بالرجوع إلى معاجم اللغة العربية، بند أن لفظ المناظرة مصدر على وزن مفاعلة، فعله ناظر، وهو من أصل ثلاثي، ومادته - النون والظاء والراء - و وزنه مفاعلة. وفي الغالب فإن صيغة المفاعلة في اللغة العربية تدل على المشاركة بين اثنين أو أكثر، كما في المقاتلة والمشاتمة ونحو ذلك. وهي من حيث الدلالة تطلق على عدة معان، منها: الأول : ناظرت فلانا :أي صرت نظيرا له في المخاطبة، وذلك إذا باحثته

$$
\text { وباريته في المحاجة. }
$$

الثاني : وناظرت فلانا بفلان :أي جعلته نظيرا له.

الثالث : يقال - أيضا :- تناظر القوم :نظر بعضهم إلى بعض، وتناظروا في الأمر :تجادلوا وتراوضوا3. - مان.

إن كلمة المناظرة في اللغة العربية لفظ ذو دلالة محددة ومعينة في اصطلاح العلوم

والفنون، حيث لقد ذهب من عرفوا المناظرة اصطلاحا إلى القول: إها تعني فن الحوار، أو النظر بالبصيرة والفكر المنطقي من الجحانبين حول موضوع قابل للجدل والمناقشة من أجل الوصول إلى رؤية متوافقة بعد تقديم الحجج المقنعة، وهي في النهاية فن قصد به الدفاع عن الرأي بالحجة الدامغة والبراهين الساطعة4.

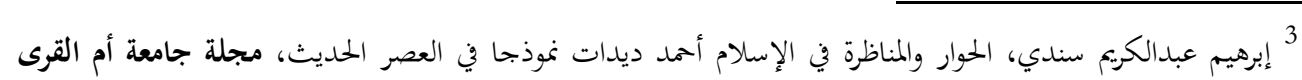

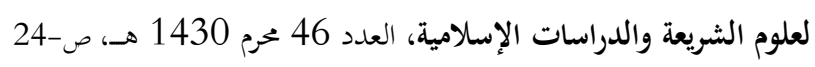

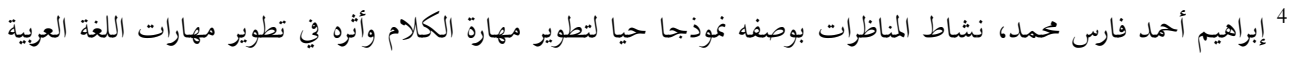

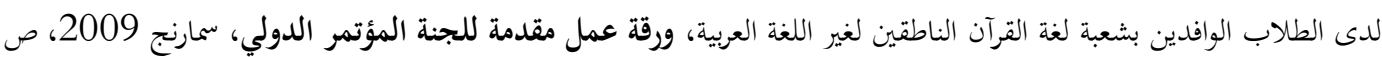


وأضاف إبراهيم قائلا أن المناظرة هي نوع من المحاورة، يشترك فيها اثنان أو أكثر،

ويتخذ كل منهما موقفا معينا يدافع عنه بالأدلة والبراهين، محاولا تأييد رأيه والدفاع عنه، وابطال الرأي الآخر بالحجة، وتفنيد مزاعمه. أي تعني أها مناقشة بين فريقين يتولى كل

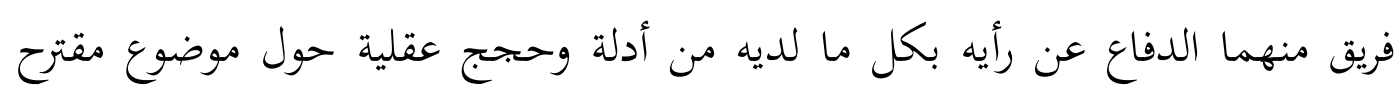
بغرض التدرب على إتقان مهارات اللغة العربية.5.

ولا يختلف ذلك قول منى إبراهيم اللبودي أن المناظرة تتضمن حوارا بين فريقين كل منهما يتبنى وجهة نظر غختلفة بشأن موضوع أو قضية جدلية، ويقوم كل فريق الريق بإعداد ملخص للأفكار والآراء التى يينى عليها وجهة نظره يعرض رئيس الفريق . ويتضح من هذه التعريفات أن المناظرة هي حوار بين شخصين أو فريقين لتبادل

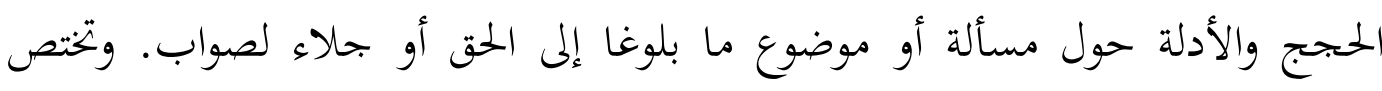
المناظرة في هذا البحث هي نشاط طلابي لغوي يغلب عليه الجانب الشفهي. والهدف منها التزكيز على تعلم مهارة الكلام لدى الطلبة.

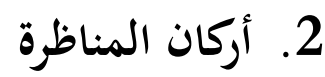

لا يمكن أن تنعقد المناظرة إلا بوجود عدة أطراف، لأن أصل لفظ المناظرة من حيث المنظور اللغوي من المفاعلة، ومصدر المفاعلة يعني :التشارك بين اثنين فأكثر. ومن هذا المنطلق يلزم أن نحد الأركان التي بوجودها تنعقد المناظرة. وضع إبراهيم عبد الكريم ركنين في المناظرة، هما: - مان

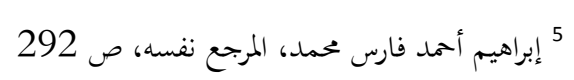

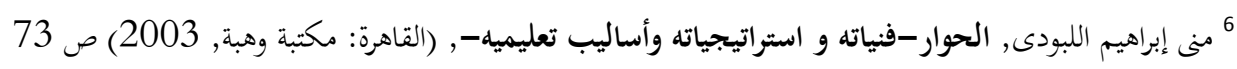




$$
\text { الركن الأول : الموضوع }
$$

هو القضية التي ستجري حولها المناظرة، وتكون صورته مشخصة في ذهن كل المتناظرين، محدودة المعالم، معينة الأهداف، أي بعبارة أخري

$$
\text { أن الموضوع لابد قابلا للاختلاف حوله. }
$$

الركن الثاني : المتناظران

وهما الطرفان اللذان سيتحاوران حول الموضوع المطروح للمناظرة،

ويسمى أحدهما مدعيا أو ناقل خبر والآخر :معترضا عليهُ7.

ولا يختلف ذلك قول اللبودي بأن يشترط للمناظرة وجود طرفين، هما المتناظران أو، يكونا على علم بموضوع المناظرة وبالقواعد التى بتحى المناظرة على أساسها، ويشترط كذلك وجود موضوع يجرى التناظر فيه، ويشترط أن يكون قابلا للاختلاف حوله، أي يكون محل جدال ويحسن ألا يكون فيه إساءة أو إثارة للمشاعر .8

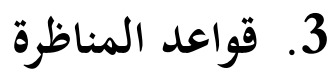

هناك توجيهات قرآنية إلى القواعد العامة للمناظرة أو الجحدل بالتي هي أحسن، من هذه التوجيهات وضعت قواعد علمية دقيقة، وبها ترجى أن تتم عملية والمناظرة

$$
\text { بنجاح. و هاهي من أبرز قواعد المناظرة: }
$$

على المناظر أن يكون ذا بصيرة بالأساليب المنطقية السليمة عند المناظرة،

" إبرهيم عبد الكريم سندي، الحوار والمناظرة في الإسلام أممد ديدات نموذجا في العصر الحديث، مجلة جامعة أم القرى

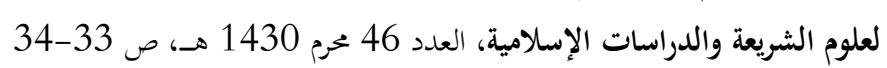

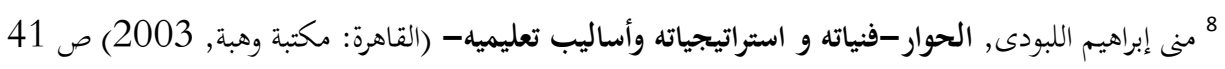


وبمبادئها: كي تأخذ عملية الجمدال والمناظرة مسارا صحيحا، ويسودها جو التفاهم والتسامح، وإلا تحولت إلى جولات كلامية عقيمة، حصادها الفشل وإضاعة الوقت. القاعدة الثاينة : التحلي بالقول المهذب. يجب على كل من كان طرفا في الجدال أن ينزه لسانه عن كل ما فيه إيذاء للطرف الآخر، وعن كل ما من شأنه أن يبعث على استثارة مشاعر الغضب في النفس من طعن، أو بتريح، أو هزء، أو سخرية: فالمناظر مطالب فجداله بالتزام جانب الأدب، والسلوكيات العالية: لإثبات الحق الذي يؤمن به، وإقناع الآخرين به على أحسن وجهه من المجادلة القاعدة الثالثة :عدم تناقض أقوال المناظر بعضها ببعض. ألا تكون الدعوى التى يقدمها المناظر مناقضا بعضها بعضا، فإن ذلك يقضى بإسقاط دليله ودعواه، فيكون قد حكم على عدم جدوى ما أدلي من دليل أو دعوى مما يساند وجهة نظهره. القاعدة الرابعة : إعلان التسليم بالمسلمات. يجب على كلٍٍ من المتناظرين أن يعلنا التسليم بالأمور والقضايا التي هي من البدهيات والمسلمات الأولى، أو الأمور المتفق بينهما على التسليم بها. القاعدة الخامسة: قبول النتائج المتوصل إليها.

لابد من الإذعان للنتائج التي تمخضت عن المناظرة، والتي توصل كلا الطرفين إليها بالأدلة القاطعة، أو المرجحة، وقبولما، لأن الدافع إلى المناظرة من أول أمرها إنما هو الوصول إلى الحقيقة، وهي الهدف الأسمى الذي ينبغي لكل ذي 
لب أن يسعى إلى البحث عنه واكتشافه، وتقبله أنّ عنّ، وظهر، وإلا عدت المناظرة مضيعة للوقت في ما لا طائل من ورائه 9. 4. المناظرة في تعليم مهارة الكلام 1- - دور أسلوب المناظرة في تعليم مهارة الكلام

المناظرة هي حوار بين متناظرين بلوغا إلى الحق أو جلاء لصواب، تتطلب التزام طرفيها بضوابط وشروط محددة وفيها يتبادل الطرفان المتناظران الحجج والأدلة حول مسألة ما. وتتطلب المناظرة مهارة من المتناظرين في توليد الأسئلة وترتيبها، وبناء الحجج والأدلة، لذلك كان على المتناظرين أن يمتلكوا مهارة السؤال (لياقة وصياغة)، ومهارة بناء الحجة (استدلالا وترتيبا) ·. وأضافت منى اللبودي أن المناظرة هي أحد الأنشطة الصفية الفعالة التى تسهم في

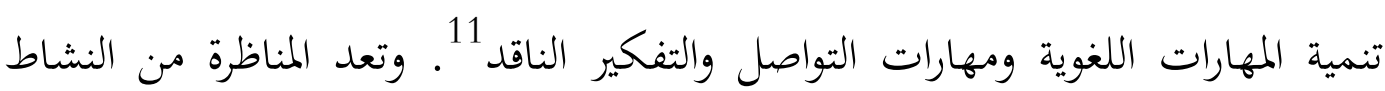
الملائم للفصول الصغيرة، حيث يقوم المدرس بتقسيم الفصل إلى بحموعتين لتقوم كل واحدة بتبني وجهة نظر معينة والدفاع عنها. وتتيح المناظرة فرصة للعمل الجماعي والتبادل الآراء، وهما أمران من السلوكيات الراسخية في التفاعل داخل المختمعات الأكاديمية. وتفيد المناظرة أيضا في صقل مهارة التعبير من عدة نواحي، خاصة في الاتصالية. وهي من الناحية العملية سهلة التنفيذ وقادرة على جذب الطلاب واستدعاء انفعالاتمم الذهنية والنفسية. 2- - فوائد أسلوب المناظرة في تعليم مهارة الكلام

9 إبرهيم عبد الكريع سندي، الحوار والمناظرة في الإسلام أممد ديدات نموذجا في العصر الحديث. مجلة جامعة أم القرى

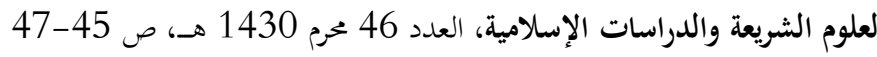

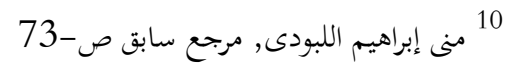

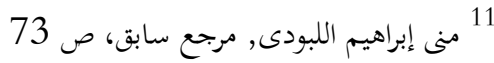


تعتبر المناظرة من الأنشطة الصفية الفعالة في تحسين الطلاقة الشفهية ومهارات الاستماع، كما أغا كطريقة للتدريس تزيد من دافعية الطلاب، وتحسن من فهمهم للموضوعات، وتنمى مهارات التفكير الناقد والتحليل والتركيب، فضلا عن مهارات التحدث 12

وقال إبراهيم أحمد أن النتائج المحقة التى يكسبها الطلاب من التدريب على فن

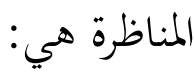

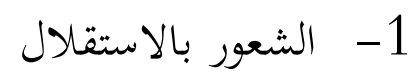

إحساس الطالب بالقدرة على الاستقلال، وليس معناه هنا البعد عن الناس وعدم التفاعل معهم، وإنما الذي هو أن يكون للمشارك في نشاط المناظرات كيان خاص مستقل بذاته مع الاعتماد في الوقت ذاته على الآخرين والتعاون معهم وتطوير عمليات الاتصال اللغوي والاجتماعي مع الآخرين.

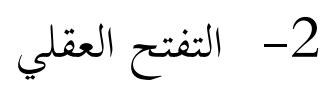

قيام الطالب بتقبل رؤي الآخرين -اعتراضات، أراء مستجدة، ردودبفتح مزيد من قنوات الاتصال معهم وبشكل معمق، عن طريق ذاته الداخلية الواثقة، مما يسمح له ويمكنه من التعبير عن نفسه ومشاعره للآخرين بصدق وعمق، بعيدا عن التصنع والسطحية مستعينا بلقة عربية راقية أداءا وتعبيرا.

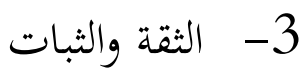

ازدياد ثقة الطالب أو الدارس بشعبة لغة القرآن بنفسه وبالآخرين وبالعالم المحيط به ومن حوله، وكذلك الثقة بمشاعره الشخصية وأحاسيسه. 12 منى إبراهيم اللبودى, الحوار - فنياته و استراتيجياته وأساليب تعليميه- (القاهرة: مكتبة وهبة, 2003)، ص 75 


$$
\text { 4- 4- العلاقة مع الجمهور }
$$

من منظور فن المناظرة كونه فنا من فنون الخطاب الجماهيري بمعنى أن التناظر يتم أمام عدد مقدر من الجمهور، وعليه لابد من إقامة جسور للتواصل مع هذا الحمهور من حيث: توجه الخطاب، وتقديم الحجج، وإثارة

$$
\text { 5- تنمية القدرة على التفكير العلمي، وتقديم التفسيرات، والحركات التعبيرية. }
$$

إن مايمز الإنسان عن سائر الكائنات الأخرى هو العقل الذي وهبه الله

تعالي، وبناء على ذلك فإن التدريب على المناظرة يركز على تنمية قدرة

$$
\text { الطالب على التفكير. }
$$

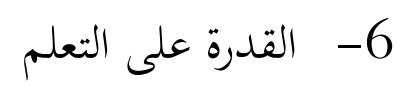

القدرة على التعلم تعد إحدى ميزات السلوك السوي للطلاب في

التدريب على المناظرة، وهذا التعلم يتم عن طريق الممارسة الفعلية المهمات،

$$
\text { 7- احترام العمل وتقديره طريق الملاحظة، أو الاستفادة من أخطاء الزملاء. }
$$

من القيم الإيجابية التي يتعلمها الطالب من التدريب على فن المناظرة احترام الطالب المتدرب على المناظرة العمل العام، والمشاركة الوجدانية

$$
\text { 8- التعاون والعمل الجماعي والنظر إليه بوصفه قيمة بحد ذاته. }
$$


تحقيق التفوق الأكاديمي في المواد الدراسية التي يدرسها الطلاب بوسيلة

$$
\begin{aligned}
& \text { التعاون أو الروابط الاجتماعية والإنسانية بينهم } 13 \\
& \text { 3- تطبيق أسلوب المناظرة في تعليم مهارة الكلام }
\end{aligned}
$$

بعد أن نعرف دور أسلوب المناظرة وفواعده في تعليم مهارة الكلام يشرح

\begin{tabular}{|c|c|}
\hline عملية الطلبة في تعليم مهارة الكلام باستخدام & 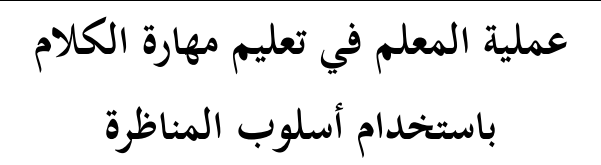 \\
\hline 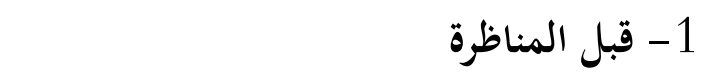 & 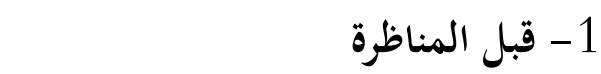 \\
\hline • التدريب وكتابة المفردات الجديدة & • إعطاء المفردات الجديدة المتعلقة \\
\hline & بالموضوع وتدريبها \\
\hline ••اهتمام بتقديم الموضوع من المعلم & • تقديم الموضوع أو المادة بحملا \\
\hline • يجتمع الطلاب حسب فرقتهم & • تقسيم الطلاب إلى ست فرق تتكون \\
\hline & كل فرقة من أربعة طلاب عدم \\
\hline & متجانسين في الكفاءة والشخصية \\
\hline & 2- اجراء المناظرة \\
\hline 2- اجراء المناظرة & • توزيع المادة الدراسية (السياحة البحرية \\
\hline • استلام المادة الدراسية (السياحة البحرية في & في لامونجان) لكل فرق \\
\hline ل الاموبحان) & • تنظيم المناقشة لكل الفرقة \\
\hline • يتناقش الطلاب في فرقهم & • إقتراع الفرقة إلى الفريق المؤيد والفريق \\
\hline • أخذ الإقتراع (الفريق المؤيد والفريق المعارض) & المعارض للمناظرة \\
\hline 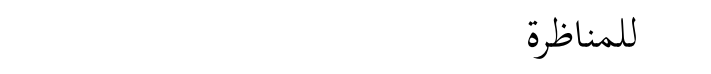 & • تنظيم عملية المناظرة للفريقين (الفريق \\
\hline عملية المناظرة & المؤيد والفريق المعارض) متبادلا حسب \\
\hline
\end{tabular}
الباحث كيفية تطبيق أسلوب المناظرة في تعليم مهارة الكلام في الجدول التالى:

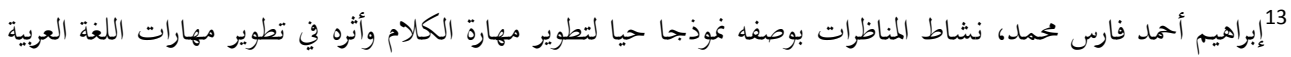

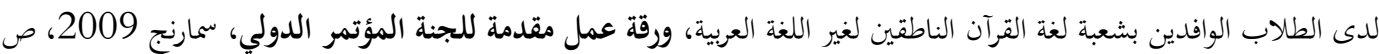




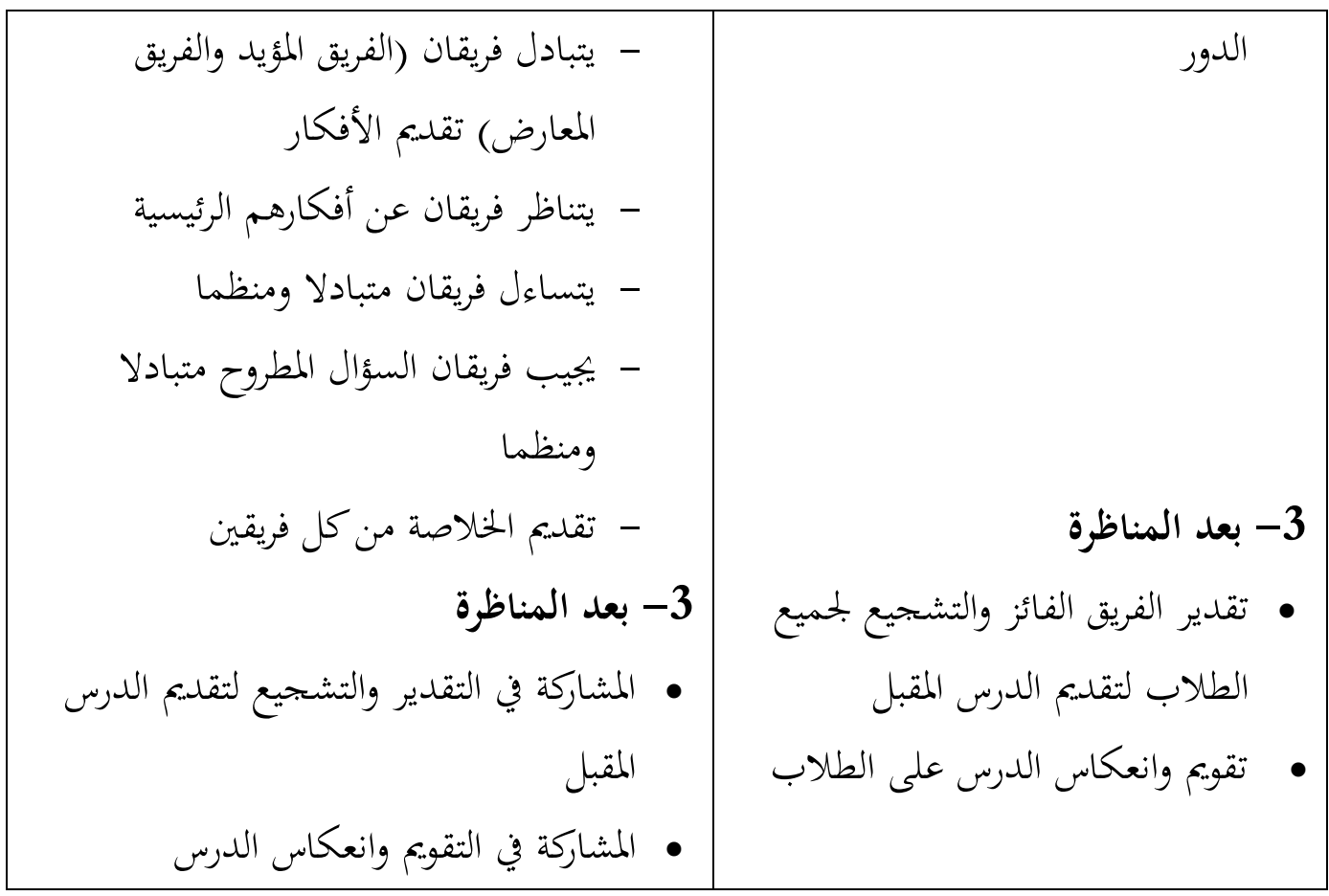

\section{المدخل الفعال}

\section{أ- ت تعريف المدخل الفعال}

ظهرت الحاجة إلى التعلم الفعال نتيجة عوامل عدة، لعل أبرزها حالة الحيرة والارتباك التي يشكو منها المتعلمون بعد كل موقف تعليمي، والتي يمكن أن تفسر بأفها نتيجة عدم اندماج المعلومات الجلديدة بصورة حقيقية في عقولمم بعد كل نشاط تعليمي تقليدي. ويقصد بالمخدل الفعال أو التعلم الفعال هو اشتراك الطلاب في عملية التعلم والتعليم بشكل فعال أو نشاط ليسير التعليم بصورة جيدة وتحقق أهداف التعليم المقررة

${ }^{14}$ Machmudah dkk, Active learning dalam pembelajaran Bahasa Arab, (Malang : UIN Malang Press, 2008). h. 61 
بينت نتائج الأبحاث مؤخرا أن طريقة المحاضرة التقليدية التي يقدم فيها المعلم المعارف وينصت المتعلمون خلالها إلى ما يقوله المعلم هي السائدة. كما تبين أن هذه الطريقة لا تسهم في خلق تعلم حقيقي. و ظهرت دعوات متكرة إلى تطوير طرق تدريس تشرك المتعلم في تعلمه.

إن إنصات المتعلمين في غرفة الصف سواء أكان لمحاضرة أم لعرض بالحاسب لا يشكل بأي حال من الأحوال تعلما فعالا. لكي يكون التعلم فعالا ينبغي أن ينهمك المتعلمون في قراءة أو كتابة أو مناقشة أو حل مشكلة تتعلق بما يتعلمونه أو عمل بتحيبي، و بصورة أعمق فالتعلم الفعال هو الذي يتطلب من المتعلمين أن يستخدموا مهام تفكير عليا كالتحليل والتركيب والتقويم فيما يتعلق بما يتعلمونه. بنـاء على ما سبق فإن التعلم الفعال هـو: طريقة تدريس تشترك المتعلمين في عمل أشيـاء تجبرهم على التفكير فيما يتعلمونه 15

بينت محمودة الفرق بين المدخل الفعال والمدخل التقليدي في التعليم كما يلى 16:

\begin{tabular}{|c|c|c|}
\hline المدخل الفعال & المدخل التقليدي & 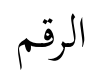 \\
\hline ترتكز عملية التعلم والتعليم على & ترتكز عملية التعلم والتعليم على & 1 \\
\hline 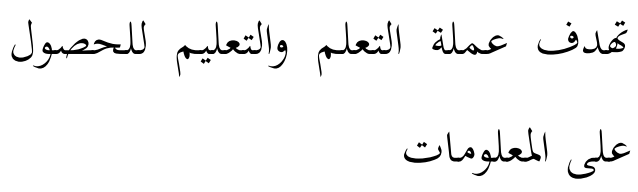 & 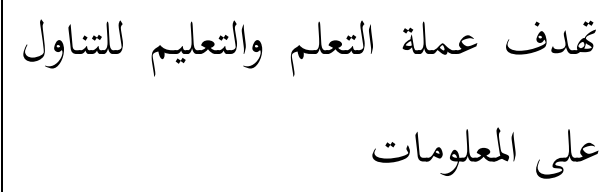 & 2 \\
\hline عملية التعلم والتعليم جذابة ومتععة & ومملية التعلم والتعليم غير جذابة & 3 \\
\hline
\end{tabular}

15 عمرو سلم، التعلم الفعال، hattp://AMRSELIM.net، (3 إبريل 2012)

${ }^{16}$ Machmudah dkk, Active learning dalam pembelajaran Bahasa Arab, h. 61 


\begin{tabular}{|c|c|c|}
\hline مركز باشتراك الطلاب في عملية التعلم & عدم اشتراك الطلاب في عملية التعلم & 4 \\
\hline بمعلومات الطلاب المادة التعليمية المناسبة & 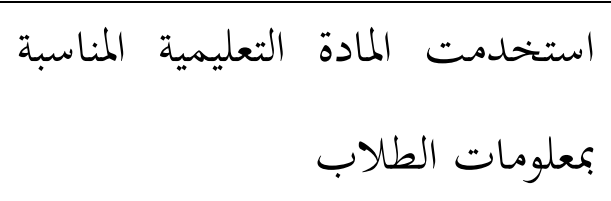 & 5 \\
\hline
\end{tabular}

\section{ب- - خصائص المدخل الفعال}

باستخدام المدخل الفعال في التعليم يتطلب الطلاب اشتراك التعلم بجد ونشاط.

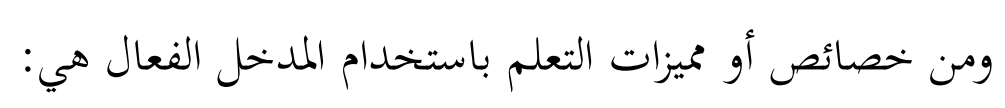

أ- يتوصل المتعلمون خلال التعلم الفعال إلى حلول ذات معنى عندهم للمشكلات, لأفم يربطون المعارف الجحديدة أو الحلول بأفكار وإجراءات

$$
\text { مألوفة عندهم وليس استخدام حلول أشخاص آخرين. }
$$

ب-يجصل المتعلمون خلال التعلم الفعال على تعزيزات كافية حول فهمهم

$$
\text { للمعارف الجديدة }
$$

ج- الحاجة إلى التوصل إلى ناتج أو التعبير عن فكرة خلال التعلم الفعال تحبر المتعلمين على استرجاع معلومات من الذاكرة ربما من أكثر من موضوع ثم

ربطها ببعضها، وهذا يشابه المواقف الحقيقية التي سيستخدم فيها المتعلم المعرفة.

د- يبين التعلم الفعال للمتعلمين قدرقم على التعلم بدون مساعدة سلطة، و هذا

$$
\text { يعزز ثقتهم بذواتم و الاعتماد على الذات. }
$$

هـ - يفضل معظم المتعلمين أن يكونوا نشطين خلال التعلم. 
و - المهمة التي ينجزها المتعلم بنفسه خحلال التعلم الفعال, أو يشترك فيها تكون

$$
\text { ذات قيمة أكبر من المهمة التي ينجزها له شخص آخر. }
$$

ز - يساعد التعلم الفعال على تغيير صورة المعلم بأنه المصدر الوحيد للمعرفة، وهذا

له تضمين هام في النمو المعرفي المتعلق بفهم طبيعة الحقيقة.

ح- يتعلم المتعلمون من خلال التعلم الفعال أكثر من المحتوى المعريف، فهم يتعلمون مهارات التفكير العليا، فضلا عن تعلمهم كيف يعملون مع آخرين يختلفون

عنهم. (- من

ط- يتعلم المتعلمون خلال التعلم الفعال استراتيجيات التعلم نفسه - طرق الحصول

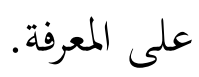

\section{تعليم مهارة الكلام}

\section{أ- مهارة الكلام: تعريفها وأهميتها}

الكالام في أصل اللغة عبارة عن الأصوات المفيدة، وعند المتكلمين هو المعنى القائم بالنفس الذي يعبر عنه بألفاظ. وفي اصطلاح النحاة: الجملة المركبة المفيدة. وأما التعريف الاصطلاحي للكلام فهو: الكلام المنطوق الذي يعبر به المتكلم عما في نفسه من: هاجسه، أو خاطره، وما يجيول بخاطره من مشاعر وإحساسات، وما يزخربه عقله من : رأي أو فكره، وما يريد أن يزود به غيره من معلومات، أو نحو ذلك، في طلاقة

$$
\text { وانسياب، مع صحة في التعبير وسلامة في الأداء } 17 .
$$

17 أحمد فؤاد محمود عليان، المهارات اللغوية وأهميتها و طرائق تدريسها (الرياض: دار المسلم للنشر و الوزيع، 1431 
وقالت منى إبراهيم اللبودي الكالام هو فن نقل المعتقدات والمشاعر والأحاسيس

والمعلومات والمعارف والخبرات والأفكار والأراء من شخص إلى آخرين نقلا يقع من المستمع أو المستقبل أو المخاطب موقع القبول و الفهم و والتفاعل والاستجابة 18. وأضاف الناقة أن الكلام هو مهارة انتاجية تتطلب من المتعلم القدرة على استخدام الأصوات بدقة، والتمكن من الصيغ النحوية ونظام ترتيب الكلمات التي تساعده على التعبير عمّا يريد أن يقوله في مواقف الحديث 19. ويتضح من هذه التعريفات أن الكلام وسيلة الاتصال الشفهي أي وسيلة التعبير الشفهية من شخص إلى الآخرين ليرسل الرسالة عما يريد، ويعتبر الكلام في اللغة الثانية من المهارات الأساسية التي تمثل غاية من غايات الدراسة اللغوية. لاشك أن الكلام من أهم ألوان النشاط اللغوي للصغار والكبار، فالناس يستخدمون الكلام أكثر من الكتابة، أي أهم يتكلمون أكثر مما يكتبون، ومن ثم نستطيع أن نعتبر أن الكلام هو الشكل الرئيسي للاتصال بالنسبة للإنسان ومن هنا فهو يعتبر أهم جزء في ممارسة اللغة واستخدامها ل20.

الكالام من المهارات الأساسية، التي يسعى الطالب إلى إتقاها في اللغات الأجنبية21. تظهر أهمية تعليم الكلام في اللغة الأجنبية من أهمية الكلام ذاته في اللغة. فالكام يعتبر جزءا رئيسا في منهج تعليم اللغة الأجنبية، ويعتبره القائمون على هذا

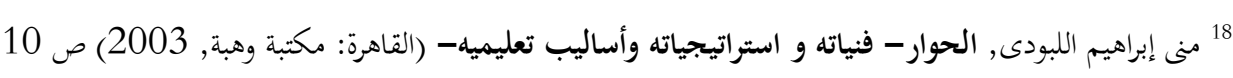

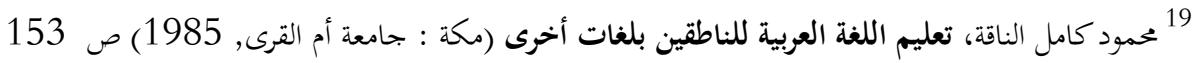

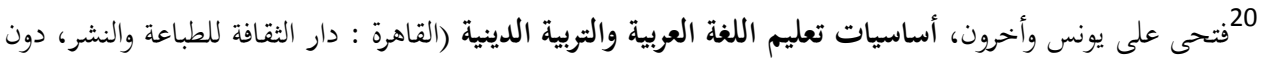

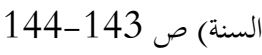
لملك فيد البعد الرمن بن إبراهيم الفوزان، إضاءات لمعلي اللغة العربية لغير الناطقين بها، الطبعة الأولى (الرياض: فهرسة

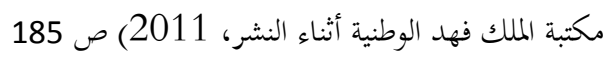


الميدان من أهم أهداف تعلم لغة أجنبية، ذلك أنه يمثل في الغالب الجزء العملي والتطبيقي لتعلم اللغة.22.

\section{ب- - أهداف تعليم مهارة الكلام}

إن اللغة تتمثل من أربعة فنون هي الاستماع والكلام والقراءة والكتابة. ولكل فن

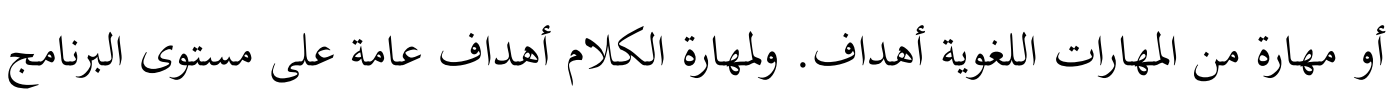

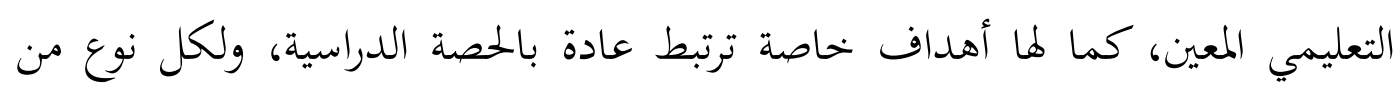
هذين النوعين صياغة لغوية تختلف عن الأخرى 23.

وفيما يلي الأهداف العامة لمهارة الكلام لغير الناطقين بما كما يشير بذلك كثير

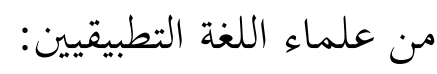
1- أن نطق الأصوات نطقا صحيحا.

2- التمييز عند النطق، بين الأصوات المتشاهة تمييزا واضحا. 3- التمييز عند النطق بين الحركات القصيرة وبين الحركات الطويلة. 4- تأدية أنواع النبر والتنغيم بطريقة مقبولة. 5- اختيار التعبيرات المناسبة للمواقف المختلفة

6- استخدام عبارات الجحاملة والتحية استخداما سليما في ضوء فهمه للثقافة

$$
\text { العربية. }
$$

7- استخدام النظم الصحيح لتراكيب الكلمة العربية عند الكلام.

222

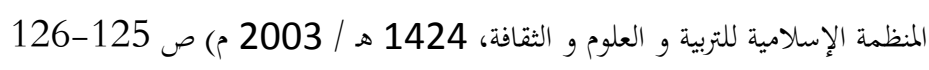

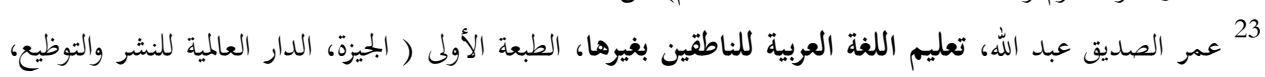

$$
76 \text { 2008 }
$$


8- - ترتيب الأفكار ترتيبا منطقيا يلمسه السامع.

9- التحدث بشكل مترابط لفترات زمنية مقبولة مما ينبع عن ثقته بالنفس وقدرته

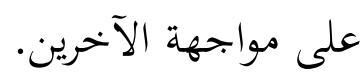

10- إلقاء خطبة قصيرة متكاملة العناصر.

11- إدارة حوار هاتفي مع أحد الناطقين تالعربية 24.

خاتمة

تتضح في المباحث السابقة أن مهارة الكلام في تعليم اللغة العربية مهارة أساسية

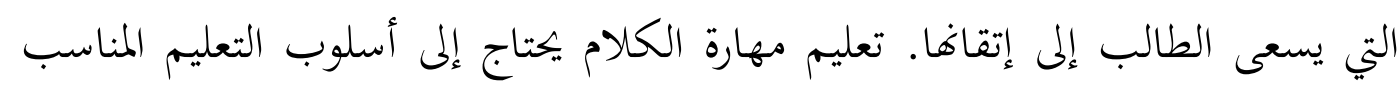

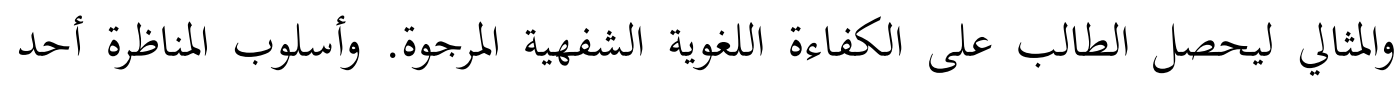

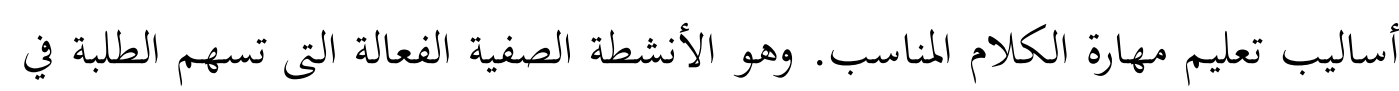
تنمية المهارات اللغوية ومهارات التواصل.

\section{المراجع بالعربية}

أممد فؤاد محمود عليان. 1431. المهارات اللغوية وأهميتها و طرائق تدريسها الرياض: دار المسلم للنشر و الوزيع.

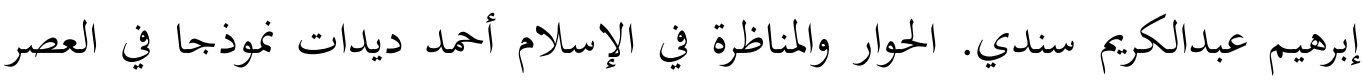

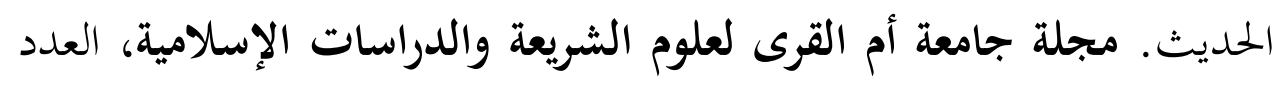
46

24 عبد الرحمن بن ابراهيم الفوزان، إضاءة لمعلمى اللغة العربية لغير الناطقين بها، الطبعة الأولى ( دون النشر،

2011)، ص: 189 
إبراهيم أحمد فارس محمد. نشاط المناظرات بوصفه نموذجا حيا لتطوير مهارة الكلام وأثره في تطوير مهارات اللغة العربية لدى الطلاب الوافدين بشعبة لغة القرآن الناطقين لغير اللغة العربية، ورقة عمل مقدمة للجنة المؤتمر الدولي، سمارنج 2009. رشدي أحمد طعيمة، دون السنة. تعليم العربية لغير الناطقين بها: مناهجه وأساليبه. الرباط: منشورات النظمة الإسلامية للتربية والعلوم والثقافة.

عبد الرحمن بن إبراهيم الفوزان. 2011. إضاءات لمعلي اللغة العربية لغير الناطقين بها، الطبعة الأولى. الرياض: فهرسة مكتبة الملك فهد الوطنية أثناء النشر. عمر الصديق عبد الله. 2008. تعليم اللغة العربية للناطقين بغيرها، الطبعة الأولى. الجيزة، الدار العالمية للنشر والتوظيع.

عمرو سلم، التعلم الفعال. http://AMRSELIM.net. مأخوذ في 3 إبريل 2012. فتحى على يونس وأخرون. دون السنة. أساسيات تعليم اللغة العربية والتربية الدينية القاهرة : دار الثقافة للطباعة والنشر. محمود كامل الناقة.1985. تعليم اللغة العربية للناطقين بلغات أخرى. مكة : جامعة النئرة أم القرى.

محمود كامل الناقة و رشدي أحمد طعيمة.1424. طرائق تدريس اللغة العربية لغير الناطقين بها. إيسيسكو: منشورات المنظمة الإسلامية للتربية و العلوم و الثقافة. منى إبراهيم اللبودى. 2003. الحوار-فنياته و استراتيجياته وأساليب تعليميه-. القاهرة: مكتبة وهبة.

نايف محمود معروف. 1985. خصائص العربية وطرائق تدريسها، الطبعة الأولى. بيروت: دار النفائس.

\section{المرجع بالإندونيسية}

Umi Machmudah dan Abdul Wahab Rosyidi. 2008. Active learning dalam pembelajaran Bahasa Arab. Malang : Uin Malang Press, 2008. 
